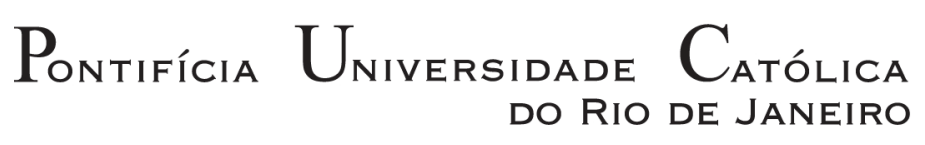

DO RIO DE JANEIRO

Hugo Borges Backx

Design e Propriedade Intelectual: vínculos e interações

Tese de Doutorado

Tese apresentada ao Programa de Pós-Graduação em Design da PUC-Rio como requisito parcial para obtenção do grau de Doutor em Design.

Orientador: Prof. Cláudio Freitas de Magalhães

Rio de Janeiro

Março de 2013 


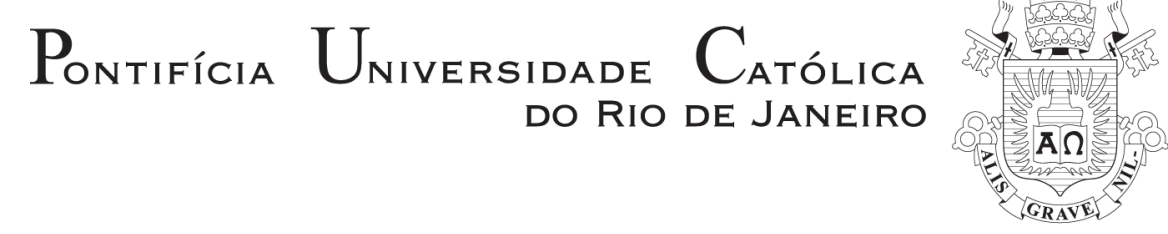

Hugo Borges Backx

\section{Design e Propriedade Intelectual: vínculos e interações}

Tese apresentada ao Programa de Pós-Graduação em Design da PUC-Rio como requisito parcial para obtenção do grau de Doutor em Design. Aprovada pela Comissão examinadora abaixo assinada.

Prof. Cláudio Freitas de Magalhães

Orientador

Departamento de Artes \& Design - PUC-Rio

Profa. Rita Maria de Souza Couto Departamento de Artes \& Design - PUC-Rio

Prof. Luiz Antônio Luzio Coelho Departamento de Artes \& Design - PUC-Rio

Profa. Patrícia Pereira Peralta Instituto Nacional de Propriedade Industrial - INPI

Dr. Cláudio Roberto Barbosa Kasznar Leonardos Propriedade Intelectual - KL

Profa. Denise Berruezo Portinari Coordenadora Setorial do Centro de Teologia e Ciências Humanas - PUC-Rio 
Todos os direitos reservados. É proibida a reprodução total ou parcial do trabalho sem a autorização da universidade, do autor e do orientador.

\section{Hugo Borges Backx}

Mestre em Engenharia de Produção COPPE/UFRJ (1994), graduado em Direito CUAM (2000), graduado em Desenho Industrial UFRJ (1986). Professor Assistente - DE no curso de Desenho Industrial - Habilitação Projeto de Produto UFRJ (desde 1986), advogado OAB/RJ 111472. Experiência na área de Design de produto, perícia judicial em contrafação de design, propriedade intelectual. Coordenador do Laboratório de Propriedade Intelectual - Lapi / UFRJ.

Ficha Catalográfica

Backx, Hugo Borges

Design e Propriedade Intelectual: vínculos e interações / Hugo Borges Backx; orientador: Cláudio Freitas de Magalhães. -2013.

281 f.: il.; $30 \mathrm{~cm}$

Tese (Doutorado) - Pontifícia Universidade Católica do Rio de Janeiro, Departamento de Artes e Design, 2013.

Inclui bibliografia

1. Artes e design - Teses. 2. Design. 3. Propriedade intelectual. 4. Taxonomia. 5. Conteúdos criativos. 6. Conteúdos criativos derivados. 7. Objetos criativos híbridos. 8. Espaços de interação. 9. Ensino-aprendizagem de PI. I. Magalhães, Cláudio Freitas de. II. Pontifícia Universidade Católica do Rio de Janeiro. Departamento de Artes \& Design. III. Título. 
Para a minha esposa e filhos, pelo amor especial que Deus abençoou e que nos uniu. 


\section{Agradecimentos}

A Deus em primeiro lugar, pois é quem nos dá sentido à vida e que está sempre presente para os que lhe reconhecem como Pai.

Ao meu orientador, Professor Cláudio de Freitas Magalhães, pelo estímulo, parceria e por ter aceitado como desafio orientar um tema complexo envolvendo áreas tão distintas como o Design e a propriedade intelectual. E, sobretudo, pela confiança depositada em mim na realização desse trabalho.

À PUC-Rio, pelos auxílios concedidos, sem os quais este trabalho não poderia ter sido realizado.

Aos demais professores do Departamento de Artes \& Design da PUC-Rio, em especial Rita Couto, Denise Portinari, Vera Nojima e Ana Maria de Moraes (in memória), pela competência e dedicação que muito contribuíram para a reflexão dos conteúdos contidos na presente tese e profissionalmente.

Aos integrantes da Comissão examinadora pela inestimável colaboração.

Aos funcionários do Departamento de Artes \& Design pela atenção e presteza no atendimento às solicitações acadêmicas.

Aos amigos e amigas que tiveram paciência comigo quando dessa minha empreitada. 


\section{Resumo}

Backx, Hugo Borges; Magalhães, Cláudio Freitas de. Design e Propriedade Intelectual: vínculos e interações; Rio de Janeiro, 2013. 281p. Tese de Doutorado - Departamento de Artes \& Design, Pontifícia Universidade Católica do Rio de Janeiro.

Esta tese refere-se ao estudo, pesquisa e fundamentação teórica dos vínculos e interações entre o Design e a propriedade intelectual (PI). As criações intelectuais em Design têm características compatíveis com a maioria das modalidades de resguardo definidas na PI. Contudo, é necessário entender corretamente o "fluxo" que estas percorrerem no sistema legal. O pouco domínio dos seus conteúdos e de suas interações acarreta dificuldades na gestão plena das criações intelectuais utilizando-se do sistema. Para permitir a compreensão do conjunto foi desenvolvida uma classificação sistematizada (taxonomia) dos conteúdos criativos da PI permitindo uma visão panorâmica do sistema a partir das características estéticas e técnicas das criações, dos conteúdos criativos derivados e dos objetos criativos híbridos. Com a taxonomia desenvolvida foi possível identificar os conteúdos criativos mínimos relacionados com cursos superiores de conteúdos projetivos e, especificamente, com habilitações e especialidades em Design. Foram tratados também dos espaços de interação entre o Design e a PI quando da coleta e análise de dados para projeto ou tomada de decisões estratégicas; da proteção, defesa, negociação e apropriação das criações intelectuais; e do exercício de novas competências pelo designer. Relacionadas com cada espaço de interação são indicadas as habilidades esperadas a serem alcançadas a partir do ensino-aprendizagem de PI. São habilidades baseadas nas recomendações de conteúdos curriculares de PI formuladas para cursos de Design.

\section{Palavras-chave}

Design; propriedade intelectual; taxonomia; conteúdos criativos; conteúdos criativos derivados; objetos criativos híbridos; espaços de interação; ensinoaprendizagem de PI. 


\section{Abstract}

Backx, Hugo Borges; Magalhães, Cláudio Freitas de (Advisor). Design and Intellectual Property: connections and interactions; Rio de Janeiro, 2013. 281p. DSc. Thesis - Departamento de Artes \& Design, Pontifícia Universidade Católica do Rio de Janeiro.

This thesis is on the study, research, and theoretical basis of the connections and interactions between design and intellectual property (IP). The intellectual creations of design encompass characteristics that are compatible with most protection modalities defined in IP. However, it is necessary to accurately comprehend their "flow" in the legal system. Limited knowledge of their contents and interactions poses difficulties in comprehensive management of intellectual creations using the system. To allow it to be understood in its entirety, a systemized classification has been developed (taxonomy) of the creative content of IP, enabling an overview of the system from the perspective of the aesthetic and technical characteristics of the creations, the derived creative content, and the hybrid creative objects. With the taxonomy, it was possible to identify the minimal creative content that corresponds to higher education courses of projective content and, specifically, to qualifications and specialties in design. Attention was also paid to the areas of interaction between design and IP related to the collection and analysis of project data or making strategic decisions; the protection, defense, negotiation, and appropriation of intellectual creations; and the exercise of new skills by the designer. The skills expected to be developed through teaching and learning IP are shown to be related to each area of interaction. These skills are based on the recommendations of the IP curriculum content, which is formulated for design courses.

\section{Keywords}

Design; intellectual property; taxonomy; creative content; derived creative content; hybrid creative objects; area of interaction; teaching and learning IP. 


\section{Sumário}

1. Introdução 17

$\begin{array}{ll}1.1 \text { Delimitações iniciais } & 17\end{array}$

1.2 Desenvolvimento do tema 26

2. Análise das interações entre o Design e a propriedade intelectual: primeiras aproximações $\quad 39$

2.1 Aspectos gerais $\quad 40$

2.2 Interações entre Design, inovação e propriedade intelectual 45

2.3 Design e a sua relação com a propriedade intelectual 50

2.4 Design e ativos intangíveis $\quad 55$

3. Taxonomia dos conteúdos criativos da propriedade intelectual 61

3.1 Processo criativo 62

3.2 Atributos estéticos e técnicos dos conteúdos criativos 67

3.3 Taxonomia do sistema legal de proteção das criações
intelectuais

3.3.1 Subtipos formais de produto 82

3.3.2 Forma plástica versus forma técnica necessária 87

3.4 Níveis da ação criativa dos conteúdos criativos 96

3.5 Síntese taxonômica 102

3.6 Conteúdos criativos derivados 108

$\begin{array}{ll}3.7 \text { Objetos criativos híbridos } & 111\end{array}$

3.8 Domínio público de conteúdos derivados e de objetos
híbridos

$\begin{array}{ll}3.9 \text { A taxonomia no Design } & 128\end{array}$

4. Vínculos e interações dos conteúdos criativos com o Design 130

4.1 Conteúdos criativos de propriedade intelectual em Design 137

4.2 Formação em Design e a sua relação com a propriedade intelectual

5. Espaços de interação do Design com a propriedade intelectual 157

5.1 Coleta e análise de dados 158 
5.1.1 Conteúdos expressivos

5.1.2 Conteúdos de formas funcionais e dispositivas, produto e processo

5.1.3 Conteúdo marcário 167

5.2 Proteção e defesa 169

5.2.1 Defesa da criação (aspectos gerais) 185

5.3 Negociação e Apropriação 196

5.4 Novas competências 206

6. Conclusão 214

6.1 Desdobramentos e sugestões 221

7. Referências bibliográficas 223

8. Glossário 238

9. Anexos 241

9.1 Lei de Propriedade Industrial - $n^{\circ}$ 9.279/96 241

9.2 Direito de Autor - $n^{\circ}$ 9.610/98 267 


\section{Lista de figuras}

Figura 1: Espaço de interação entre Design e PI 27

Figura 2: Interação de conteúdos 31

Figura 3: Organização dos conteúdos do trabalho 38

Figura 4: Relação entre Design x inovação x PI 40

Figura 5: Relação entre design e propriedade intelectual 49

Figura 6: Interações entre Design, inovação e propriedade intelectual $\quad 49$

Figura 7: Interações entre design, inovação e propriedade intelectual

Figura 8: Conteúdos do Design $\quad 70$

Figura 9: Ramos de proteção de um produto hipotético 72

Figura 10: Estampa 73

Figura 11: Calça jeans $\quad 74$

Figura 12: Forma gráfica de produto 83

Figura 13: Forma plástica de produto 83

Figura 14: Forma funcional de produto $\quad 85$

Figura 15: Forma dispositiva de produto $\quad 86$

Figura 16: Forma funcional e forma plástica $\quad 88$

Figura 17: Formas indeferidas como forma plástica 90-91

Figura 18: Formas plásticas de produtos técnicos $\quad 92-93$

Figura 19: Forma plástica de produto técnico deferido e
indeferido

Figura 20: Desdobramentos do tipo produto 95

Figura 21: Fronteiras do estado da técnica, domínios, informações e conteúdos novos 102

Figura 22: Vínculos taxonômicos 104

Figura 23: Processo e produto do processo 105

Figura 24: Objeto criativo de proteção híbrida 109

Figura 25: Objetos criativos com conteúdos expressivos e

Figura 26: Objeto criativo híbrido 1

Figura 27: Objeto criativo híbrido 2 
Figura 28: Objeto criativo híbrido 3

Figura 29: Vínculos híbridos possíveis do desenho industrial 115

Figura 30: Objeto híbrido 4

Figura 31: Partes componentes $\quad 126$

Figura 32: Partes destacáveis $\quad 127$

Figura 33: Conteúdo de processo $3 \quad 136$

Figura 34: Design de Produto 142

Figura 35: Design de Joia 143

Figura 36: Design de Interiores 143

Figura 37: Design Ergonômico 144

Figura 38: Design de Interface 144

Figura 39: Design de Moda 145

Figura 40: Design Gráfico 145

Figura 41: Design - Mídia Digital 146

Figura 42: Design - Ilustração 146

Figura 43: Detalhes do pedido de patente de invenção 163

Figura 44: Detalhes do sistema de fechamento da tampa 171

Figura 45: Outras patentes requeridas pela Clever Pack 172

Figura 46: Relações de autoria e titularidade de conteúdo criativo no ensino $\quad 177$

Figura 47: Registros de desenho industrial de universidades $1 \quad 182$

Figura 48: Registros de desenho industrial de universidades $2 \quad 183$

Figura 49: Registros de desenho industrial de universidades $3 \quad 184$ 


\section{Lista de imagens}

Imagem 1: Tênis Crômic $\quad 57$

Imagem 2: Garrafa Conde de Osborne $\quad 75$

Imagem 3: Marca tridimensional Alpino 111

Imagem 4: Anel Puzzle Mix 119

Imagem 5: Objetos criativos híbridos $\quad 120$

Imagem 6: Conteúdo de processo 1

Imagem 7: Conteúdo de processo 2

Imagem 8: Folha de rosto de pedido de patente de invenção 162

Imagem 9: Publicação de formas plásticas concedidas - página

inicial 164

Imagem 10: Informações na RPI da marca tridimensional "Martell" 167

Imagem 11: Tampa CP 1.1 da Clever Pack 170

Imagem 12: Aplicações das tampas 173

Imagem 13: Pedido de patente de salto comutável pela UFRJ 178

Imagem 14: Contrafação da marca "QBOA" 186

Imagem 15: Contrafação da marca registrada "BR" 187

Imagem 16: Mr. Cat x Mr. Foot 189

Imagem 17: Leite de Rosas x Leite de Flores 191

Imagem 18: Reportagem sobre contrafação em design de joias 195

Imagem 19: Laudo pericial (imagens 08 a 10) 209 


\section{Lista de quadros}

Quadro 1: Tipos de criações estéticas (Lastres)

Quadro 2: Legislações nacionais relacionadas com a propriedade intelectual

Quadro 3: $1^{\circ}$ recorte entre propriedade intelectual e Design

Quadro 4: $2^{\circ}$ recorte entre propriedade intelectual e Design

Quadro 5: Requisitos legais para as interações entre Design e propriedade industrial

Quadro 6: Intangíveis

Quadro 7: Especialidades do Design por campo de atuação

Quadro 8: Dispositivos excludentes no DA e LPI

Quadro 9: Conteúdos criativos de atributo estético e técnico e seus valores

Quadro 10: Marca nominativa e mista

Quadro 11: Tipos de conteúdos criativos e relações

Quadro 12: Tipos de conteúdos criativos - Mapa Geral

Quadro 13: Conteúdos criativos derivados e suas origens

Quadro 14: Vínculos híbridos - Quadro geral

Quadro 15: Tempo de proteção segundo os ramos

Quadro 16: Tempo de proteção segundo as modalidades

Quadro 17: Relações internas do quadro taxonômico

Quadro 18: Interações internas entre Design e PI (critério)

Quadro 19: Conteúdos criativos e suas relações com cursos superiores

Quadro 20: Conteúdos criativos da PI em Design 1

Quadro 21: Conteúdos criativos da PI em Design 2

Quadro 22: Conteúdos de PI em cursos de Design

Quadro 23: Resumo dos conteúdos de PI em cursos de Design

Quadro 24: Espaços de interação entre o Design e a PI - Quadro geral

Quadro 25: Interações da PI no processo de projeto

Quadro 26: Evidências empíricas e habilidades esperadas para a coleta e análise de dados 
Quadro 28: Registros de desenho industrial por universidades de 2007 a 2011

Quadro 29: Evidências empíricas e habilidades esperadas para a proteção e defesa das criações intelectuais

Quadro 30: Formas de pagamento

Quadro 31: Evidências empíricas e habilidades esperadas para a negociação e apropriação das criações intelectuais

Quadro 32: Evidências empíricas e habilidades esperadas para o exercício de novas competências em propriedade intelectual

Quadro 33: Desdobramentos e sugestões 


\section{Lista de siglas}

CUP Convenção da União de Paris

DA Direito de autor ou direito autoral

DI Desenho Industrial

EBA Escola de Belas Artes - UFRJ

EPO European Patent Office

ICSID International Council Design of Societies of Industrial Design

INPI Instituto Nacional de Propriedade Industrial

JPO Japanese Patent Office

LPI Lei de Propriedade Industrial

MA Marca

MU Modelo de utilidade

OE Obra expressiva

OCDE Organização para Cooperação e Desenvolvimento Econômico

OMPI Organização Mundial de Propriedade Intelectual

PI Patente de invenção (verificar o contexto)

PI Propriedade intelectual (verificar o contexto)

PCT Patent Cooperation Treaty

RPI Revista de Propriedade Industrial

USPTO United States and Trademark Office

WIPO World Intellectual Property Organization 
Nem tudo o que escrevo resulta numa realização, resulta mais numa tentativa. O que também é um prazer. Pois nem tudo eu quero pegar. As vezes quero apenas tocar. Depois, o que toca às vezes floresce e os outros podem pegar com as duas mãos.

Clarice Lispector, A Descoberta do Mundo 